NBER WORKING PAPER SERIES

\title{
TEMPORARY AGENCY EMPLOYMENT AS A WAY OUT OF POVERTY?
}

\author{
David Autor \\ Susan Houseman \\ Working Paper 11742 \\ http://www.nber.org/papers/w11742
}

\author{
NATIONAL BUREAU OF ECONOMIC RESEARCH \\ 1050 Massachusetts Avenue \\ Cambridge, MA 02138 \\ November 2005
}

This manuscript was written as a chapter for Working but Poor: How Economic and Policy Changes are Affecting Low-Wage Workers, edited by Rebecca Blank, Sheldon Danziger, and Robert Schoeni. Lillian Vesic-Petrovic provided excellent research assistance throughout the project. We thank Mary Corcoran and the editors of this volume for excellent comments, Erica Pavao and Lauren Fahey for assistance in conducting interviews, and Claire Black for transcribing interviews. The Russell Sage Foundation and the Rockefeller Foundation provided support for this research. The views expressed herein are those of the author(s) and do not necessarily reflect the views of the National Bureau of Economic Research.

(C2005 by David Autor and Susan Houseman. All rights reserved. Short sections of text, not to exceed two paragraphs, may be quoted without explicit permission provided that full credit, including $\odot$ notice, is given to the source. 
Temporary Agency Employment as a Way out of Poverty?

David Autor and Susan Houseman

NBER Working Paper No. 11742

November 2005

JEL No. I38, J20, J30, J40

\begin{abstract}
The high incidence of temporary agency employment among participants in government employment programs has catalyzed debate about whether these jobs help the poor transition into stable employment and out of poverty. We provide direct evidence on this question through analysis of a Michigan welfare-to-work program in which program participants were randomly allocated across service providers ('contractors') with different job placement practices. We draw on a telephone survey of contractors and on administrative program data linked with wage records data on all participants entering the program over a three-and-a half-year period. Our survey evidence documents a consensus among contractors that temporary help jobs are generally easier for those with weak skills and experience to obtain, but no consensus on whether temporary help jobs confer long-term benefits to participants. Our analysis of the quasi-experimental data introduced in Autor and Houseman (2005) shows that placing participants in either temporary or direct-hire jobs improves their odds of leaving welfare and escaping poverty in the short term. However, we find that only direct-hire placements help reduce welfare dependency over longer time horizons. Our findings raise questions about the incentive structure of many government employment programs that emphasize rapid placement of program participants into jobs and that may inadvertently encourage high placement rates with temporary help agencies.
\end{abstract}

David H. Autor

Department of Economics

MIT, E52-371

50 Memorial Drive

Cambridge, MA 02142-1347

and NBER

dautor@mit.edu

Susan Houseman

W.E. Upjohn Institute of Employment Research

300 S. Westnedge Ave.

Kalamazoo, MI 49007-4686

houseman@upjohninstitute.org 


\section{Introduction}

One in eight Americans and one in five children under the age of six lived in poverty in 2003, according to official U.S. Census Bureau statistics. Poverty is strongly associated with lack of full-time, year-round employment. Government programs such as welfare-to-work and the Workforce Investment Act (WIA) try to help the poor find stable employment and thereby escape poverty. As one strategy to facilitate such transitions, several researchers have recently proposed the use of temporary agencies as labor market intermediaries for the poor (Holzer 2004; Andersson et al. 2005, and Lane et al. 2003). Drawing on a unique policy quasiexperiment from a large welfare-to-work program, we provide new, direct evidence on whether temporary agency jobs help low-skilled workers escape poverty.

A large minority of participants in government employment programs already work in the temporary help sector. In our data on participants in a welfare-to-work program, 21 percent who found jobs worked for temporary agencies. Similarly high levels of temporary help employment—ranging from 15 to 40 percent-have been found in other studies of government employment programs (Autor and Houseman 2002). These figures are especially striking in light of the fact that temporary agency employment accounts for only 2 to 3 percent of daily employment in the United States.

The high incidence of temporary agency employment among participants in government programs has sparked debate about whether temporary agency jobs help the poor transition into stable employment and out of poverty or instead harm their long-term labor market outcomes. Those favoring an expanded role for temporary help agencies cite evidence that some agencies provide valuable skills training, that many employers screen workers for permanent positions through agencies, and that these agencies may provide an important port-of-entry for low-skilled 
workers (Abraham 1988; Houseman 2001; Autor 2001, 2003; and Kalleberg et al. 2003). Those skeptical of an expanded role for temporary agencies tend to view most agency jobs as dead-end jobs, providing little in the way of valuable work experience, training, or opportunity for career advancement.

Both of these scenarios could be correct. In some situations, companies may use temporary agencies to screen individuals for permanent jobs with good pay, benefits, and career ladders. In these circumstances, temporary agencies may provide access for workers to good jobs. In other situations, companies may utilize temporary agencies to staff short-term positions requiring few skills and providing few chances for promotion. What matters for policy is which scenario dominates in the low-skilled markets targeted by government programs.

Our study, based on a quasi-experiment in a Michigan welfare-to-work program in one city, provides direct evidence on this policy question. Program participants were, in effect, randomly assigned among service providers (termed “contractors”). Our analysis draws on data from a survey of contractors and on administrative data linked with wage records data on all participants entering the program over a three and a half year period.

Our survey provides a detailed picture of how temporary agencies are utilized as labor market intermediaries in poor neighborhoods. It also documents considerable variation among contractors in their assessments of the consequences of temporary agency placements. Contractors with more favorable views of temporary agencies provide participants with more contact with temporary agency jobs and have higher placement rates in these positions than do contractors with less favorable views of agencies.

Using Michigan administrative welfare-to-work and wage records data, we exploit variation across contractors in the probability that statistically identical program participants will 
be placed into a temporary agency, direct-hire, or no job to identify the labor market consequences of temporary agency placements. We focus on whether, relative to a direct-hire or no job placement, temporary agency placements help participants achieve earnings sufficient to leave welfare and escape poverty.

We find that placing a participant in either a temporary or a direct-hire job improves her chances of leaving welfare and escaping poverty in the short term, defined as one quarter following the quarter of program entry. Over a one to two year time horizon, however, only direct-hire placements confer any labor market benefit. Over these longer horizons, having been placed in a temporary agency job makes a participant no better off—and possibly worse offthan not having received any job placement. Our findings contradict conclusions drawn by several previous studies and do not support policy recommendations to expand the use of temporary agencies in employment and poverty-reduction programs.

The remainder of the chapter describes the Michigan welfare-to-work program, termed "Work First," and the data; analyzes our survey data; and describes our methodology and econometric results from our administrative data. In the conclusion, we discuss plausible explanations for why we find no long-term benefit of temporary agency placements and consider the implications of our findings for policy.

\section{The Work First Program in Michigan}

A principal objective of the 1996 welfare reform legislation (the Personal Responsibility and Work Opportunity Reconciliation Act, or PRWORA) was to encourage welfare recipients to obtain jobs rapidly. The premise of welfare reform was that recipients could find stable employment and escape poverty and welfare dependency, given proper incentives and assistance in finding jobs. Pursuant to federal regulation, states generally require that those on welfare 
work as a condition of benefits receipt. Most states, including Michigan, have implemented a "Work First" strategy, in which applicants for TANF assistance who do not meet mandatory work requirements must participate in programs that help them find employment.

As the name implies, Work First programs emphasize job search assistance and rapid placement into employment. Currently, Michigan requires most TANF recipients to work 40 hours per week to remain eligible for assistance. ${ }^{1}$ Work First participants, likewise, are required to treat the program like a job and engage in program activities or search for employment for 40 hours per week until they are successful. Individuals who fail to comply with program requirements are terminated from Work First and face sanctions and, ultimately, the termination of TANF benefits.

A unique aspect of the city we study is its effective random assignment of Work First participants to Work First providers. The city is divided into geographic districts for the purpose of administering TANF and Work First programs. A state agency, the Family Independence Agency, determines welfare eligibility and administers TANF benefits. A city agency administers the Work First program, but the provision of services is contracted out. Currently, over 30 contractors, all nonprofit or public sector entities, provide Work First services. Individuals apply for TANF benefits to the Family Independence Agency servicing the district in which they reside. If applicants are deemed eligible for benefits but do not meet work requirements, they must enroll within two weeks in a Work First program run by a contractor operating in their district. In most districts, two or three contractors operate programs. In these districts, contractors take turns enrolling Work First participants. Using multiple comparison tests of participant characteristics across contractors operating in the same districts, we

\footnotetext{
${ }^{1}$ An individual may work 40 hours per week and still be eligible for TANF if her earnings are lower than a specified threshold, as determined by her family size.
} 
demonstrate that within almost all districts with two or more contractors (and within all districts included in our analysis sample), the assignment of participants to contractors is functionally equivalent to random assignment (Autor and Houseman 2005).

The Work First program structure and set of services is largely standardized among contractors. Contractors typically spend one week—40 hours—providing new participants with basic job search skills and strategies, such as skills assessment and employability planning, resume writing, interviewing and self-presentation skills, and job readiness and life-skills training. Except for "tech-prep” courses, which quickly review skills that might be tested on an employment application, little in the way of remedial, vocational, or computer skills training is provided. The availability of more intensive training is quite limited, and such courses are provided outside the Work First system to all eligible participants.

Following the first week, participants are expected to look for work full time until they are successful at finding it. At this stage, contractors play an integral role in placing participants into jobs. Virtually all of the contractors provide individual job search assistance, refer participants to jobs with specific employers, accompany participants to job fairs, bring employers on-site to recruit participants, and sponsor group job search assistance programs such as job clubs.

Once participants find suitable jobs, contractors are required to follow-up with participants and their employers on a monthly basis until the participant achieves earnings sufficient to close her TANF case, or until the participant is terminated from the program for other reasons. ${ }^{2}$ Contractors check on employment status and collect information on participants'

\footnotetext{
${ }^{2}$ Even if a participant's TANF case has been closed due to earnings, the contractor must conduct a 90-day follow-up. Typically, if a participant's case is not closed due to earnings, her Work First spell is terminated because of non-compliance with the program. The median Work First spell in our sample is slightly under three months. Ninety-six percent are terminated from the program in less than a year.
} 
wages and hours worked. This information determines whether a participant is still eligible for TANF benefits. Work First providers’ contracts with the city are written for a one-year period. The city evaluates contractors based on the fraction of participants who get jobs and on the 90day retention rate at those jobs.

\section{Data}

We draw upon two types of evidence to frame and test hypotheses about the effects of temporary agency employment on low-skilled workers. The first is a telephone survey of Work First contractors operating in our city. The second is administrative and earnings data on Work First participants who entered the program over a three and a half year period from 1999 to 2003. From these data, we utilize a sample that includes over 36,000 Work First spells and covers nine geographic districts in which 25 contractors operated programs.

\section{Telephone Survey}

We developed a survey instrument based on extensive in-person interviews with several contractors, and then pre-tested the telephone survey with another contractor. Of the 25 contractors in our sample, we completed surveys, lasting about 30 minutes, with 21; we were unable to contact two contractors, and two contractors no longer operated Work First programs. All telephone surveys were conducted between the Fall of 2004 and the Spring of 2005, a year and a half to two years following the last cohort of Work First participants represented in our administrative data. Because the survey included several open-ended questions, all surveys were tape recorded and transcribed. We interviewed the person heading the Work First program in each organization.

Part of the survey asked questions about the basic structure of the Work First program and the services provided. These questions were designed to uncover any differences across 
contractors in resources or program services that might impact outcomes of participants. As noted above, we found that the program structure and services provided are virtually identical across contractors.

Most questions focused on temporary agency jobs and agencies’ role in welfare-to-work transitions. We asked a series of questions about the contractor's policies towards working with temporary agencies to place participants into jobs, their assessments of the characteristics of temporary compared to direct-hire jobs, and their views on the long-term consequences of temporary agency employment for Work First clients. We also asked contractors a series of questions designed to help us better understand the types of temporary agencies operating in the labor market and whether and why they worked with particular agencies. Finally, we asked several questions about how participants with low-skills and poor work histories fared in temporary agency jobs as compared to those with relatively good skills and work histories. ${ }^{3}$

\section{Administrative Data}

We analyze administrative data on all Work First participants who entered the program from the fourth quarter of 1999 through the second quarter of 2003. These data include the participants' geographic district, the contractor to which each is assigned, and basic demographic information, such as race, age, gender, and educational attainment. These administrative data do not include information on family size or age of children. The unit of observation is a Work First spell, and some individuals have repeat spells. The 36,105 Work First spells represented in our data come from 23,746 participants.

\footnotetext{
${ }^{3}$ A copy of the survey instrument is available from the authors.
} 
Unlike previous studies of welfare-to-work transitions, our data provide detailed information on the jobs obtained through the welfare-to-work program. ${ }^{4}$ This information includes hourly wages, weekly hours, job title, and the name of the employer for up to six jobs obtained during a Work First spell. We coded the job titles into occupational classifications and used the employer name to identify whether the job was held with a temporary agency or not. With respect to the latter, we utilized three comprehensive lists of temporary agencies operating in our metropolitan area at various points in time represented by our data. ${ }^{5}$

\section{The Role of Temporary Agencies in Welfare-to-Work Transitions: The Views of Service Providers}

The telephone survey served several purposes. The first was to better understand how contractors place participants into jobs and the mechanisms by which they encourage or discourage placement with temporary agencies. The second was to document the range of policies and practices regarding temporary agency placements and any consensus or disagreement about the consequences of agency placements. The third was to solicit opinions about the potentially varying impacts of temporary agency employment.

\section{The Role of Contractors in Job Placements}

Contractors play an integral role in placing Work First participants into jobs. For participants who found jobs while in the program, respondents were asked to estimate what fraction found jobs on their own and what fraction they directly helped through referrals, on-site employer visits, and the like. Half of all respondents indicated they were directly involved in 75 percent or more of job placements, and all but three respondents (15 percent) took credit for

\footnotetext{
recipients.

${ }^{5}$ Particularly helpful was a list supplied by David Fasenfest and Heidi Gottfried from their study mapping the location of all temporary agencies in this metropolitan area. In a small number of cases the correct classification of an employer was unclear based on name alone, but we generally were able to determine the nature of an employer's operation through an Internet search or by contacting the employer by phone.
}

${ }^{4}$ An exception is Corcoran and Chen (2004), in which data on jobs come from interviews with welfare 
more than 50 percent of the jobs obtained in their program. Even if these estimates are inflated, they suggest that a large majority of contractors play a significant role in determining whether participants obtain jobs and, by implication, where they obtain jobs.

Seventeen of the 21 contractors provided an estimate of the fraction of employed participants obtaining work through temporary agencies. While the median response was 15 percent, there was large variation in reported estimates, with three contractors reporting that 5 percent or less of their job placements were with temporary agencies and three reporting that placements with agencies accounted for a quarter, a third, and even three-fourths of all placements. ${ }^{6}$

Table 1 reports the frequency with which contractors invite temporary help agencies to speak with or recruit participants at their Work First site and the frequency with which contractors refer participants to temporary agencies for jobs. What is most striking is the variation in the amount of contact with temporary help agencies that contractors provide their participants, especially in regard to referrals for specific jobs. Whereas five contractors (24 percent) report referring clients to temporary help jobs on a weekly basis, eight (38 percent) report making such referrals only sporadically or never.

If, as they report, contractors heavily influence the jobs that participants take, and if contractors vary substantially in the amount of exposure they provide participants to temporary agency jobs, then we should observe an association between the amount of contact with temporary agencies and the placement rate in such jobs. We computed the correlations between reported placement rates with temporary agencies and frequency of contacts with agencies,

\footnotetext{
${ }^{6}$ Although contractors do not formally track temporary agency placements, their estimates are consistent with administrative data from earlier years. The median survey response, 15 percent, compares with a mean of 21 percent from the administrative data across all years and all contractors; rates of temporary employment were somewhat lower in more recent years in our data.
} 
where the frequency is coded on a five-point scale with "never" being the lowest and "weekly" being the highest. The correlations of temporary agency placement rates with frequency of temporary agency visits and with the frequency of referrals to temporary help agencies are positive, 0.29 and 0.53 , respectively; the latter correlation is both large and significant.

\section{Contractor Views about Temporary Agencies and their Jobs}

Reflecting these differential rates of temporary agency placement, contractors differed in their assessments of the benefits and drawbacks of temporary agency jobs for participants. Contractors were asked whether their organization encouraged, discouraged, or took a neutral stance toward Work First participants taking such jobs. They were then asked to explain this position. A majority (13 of the 21) reported that their organization took a neutral stance toward temporary agency jobs; five contractors reported discouraging temporary agency jobs and three reported encouraging them.

The reasons contractors gave for these differing stances are informative. All of those who discouraged temp agency jobs and most of those who took a neutral stance mentioned that temporary agency jobs tend to be temporary and generally do not lead to permanent positions. Among this group, two contractors indicated that they used temporary help jobs only as a last resort. Even two of the three contractors who indicated that they encouraged agency positions qualified their answer by saying that they did so only in cases where the position was explicitly temp-to-hire or when direct-hire job options were poor. Striking a more positive note, four contractors stated that temporary agency positions can provide useful experience and skills to those with little prior work experience.

To obtain more systematic evidence of their views on temporary agencies, we asked contractors to rank temporary agency and direct-hire jobs on a series of characteristics, indicating 
whether temporary agency jobs are generally better, direct-hire jobs are generally better, or the two are generally about the same. The answers to this set of questions are reported in Table 2. Not surprisingly, a large majority of contractors (76 percent) viewed direct-hire jobs as superior to temporary agency jobs in terms of the duration or stability of the job. A majority (57 percent) also viewed direct-hire jobs as better or about the same as temporary agency jobs in terms of pay and hours of work. Sixty-two percent saw temporary agency jobs as better at accommodating clients' needs for flexibility or scheduling work hours. No consensus emerged as to the relative ranking of temporary agency and direct-hire jobs on transportation issues (i.e., the ease or difficulty of getting to the job), willingness to accommodate participants' special issues, and treating participants well.

\section{Differentiating among Temporary Agencies: Are Some Better than Others?}

Many contractors have strong reservations about placing workers in jobs with agencies, particularly because the assignments tend to be short term and do not lead to longer-term jobs. Perhaps as a result, contractors that work with agencies in placing participants tend to work with selected agencies. Sixteen of the 21 contractors indicated that their job developers work with particular agencies. Among those who do not work with particular agencies, it is because they seldom or never work with temporary help agencies; no contractor reported that it was open to working with all types of agencies. Among those working with selected agencies, most reported working with agencies because of specific relationships or understandings they had developed with particular agencies, because the agency regularly provided temp-to-perm opportunities, or because the agency was "honest" about the nature and length of the assignment. Three contractors stressed that they worked with agencies that have been successful at placing lowskilled, difficult-to-place workers into jobs or at placing large groups of workers into jobs. 
Among those who reported working with selected agencies, all reported having specific understandings with these agencies about the duration of job assignments and, wherever possible, that these assignments be temp-to-perm.

Just as many contractors work primarily with selected agencies, many avoid working with certain agencies. Eleven of 17 who work with agencies reported avoiding particular agencies because of bad experiences, primarily involving very short-term assignments. Some contractors discouraged participants from taking assignments with day-laborer agencies, in which participants must report to the agency in the morning and are not guaranteed an assignment. Four contractors stated that they avoid all or virtually all agencies. Differentiating among Work First Participants: Do Some Participants Do Better in Temporary Help Agency Jobs?

While contractors differentiate among types of temporary help agencies, many also distinguish between types of participants when placing them into agency jobs. Contractors were asked whether temporary agency positions were more or less difficult to obtain than direct-hire positions for those with relatively weak skills or experience and for those with relatively strong skills or experience: whether certain types of workers did better at temp agency jobs than at direct-hire jobs, and whether temp agency jobs were the only realistic alternative to unemployment for some.

Few contractors believed that temporary agency jobs are harder than direct-hire jobs for their clients to obtain. Over half viewed them as easier to obtain for those with weak skills or experience, while over a third viewed them as easier to obtain for those with strong skills or experience. About half of contractors (12 of 21) believed that certain participants do better in temporary agency jobs than in direct-hire jobs, and a third believed that those with weak skills or 
experience do better working for temporary agencies. ${ }^{7} \quad$ A large minority (43 percent) expressed the view that temporary agency jobs were the only realistic alternative to unemployment for some. Contractors holding the view that those with weak skills or experience benefit from temporary agency jobs, for the most part, coincided with those who believed that temporary agency jobs are easier than direct-hire jobs for these workers get, and indeed that such jobs may be the only alternative to unemployment for certain workers.

When asked to elaborate on why they believed participants with weak skills and experience were better off in agency jobs, several of these contractors expressed the view that some clients simply are not ready to hold a permanent job and that agency jobs give them work experience and an understanding of employer expectations. Others mentioned a valuable role that agencies can play in allowing these participants to sample different jobs and find a suitable match. Agencies can provide participants contacts with many different employers and jobs. Moreover, if participants decide that they do not like a particular job, they can request a reassignment and avoid the stigma of a quit that would be recorded if they were in a direct-hire relationship.

\section{Long-Term Consequences of Temporary Agency Placements}

The question that is most relevant for welfare-to-work policy is whether temporary agency placements foster stable longer-term employment, ideally at wages that can support a family. The preceding discussion revealed a division among contractors who felt that certain groups, particularly low-skilled participants, benefited, and those who felt that agencies conferred no benefits or even harmed workers. Contractor assessments about the long-term consequences of temporary agency placements, summarized in Table 3, reflect this division.

\footnotetext{
${ }^{7}$ The contractors who cited others as benefiting from temporary agency positions were referring to those with particular skills, such as clerical or health care, where agencies could place them into temp-to-hire positions with good companies.
} 
Contractors are most likely to feel that temporary agency placements help participants develop confidence (57 percent answered that they do so frequently or most of the time) and least likely to believe that temporary agency jobs result in temp-to-hire positions (76 percent answered rarely or occasionally). However, most striking about Table 3 is the lack of consensus among contractors about these long-term effects.

A majority of contractors (62 percent) believed that temporary agency placements can allow participants to avoid making a serious employment commitment, although there was considerable variation in contractors' assessments of the prevalence of this problem. Contractors pointed out that, even when the position is explicitly temporary, agency jobs allow participants to comply with the program's work requirements. Most contractors emphasized that many participants focus only on the short-term, and hence fail to fully appreciate that when they take a temporary agency job they are more likely to need to repeat the job search process in the near future. ${ }^{8}$

The Value of Temporary Agency Jobs: A Synthesis of the Contractors' Conflicting Views

Contractors vary widely in their policies and practices regarding the use of temporary agencies in welfare-to-work transitions. Some avoid using temporary help agencies altogether. Others use them only in selected instances where the assignments are for reputable employers who are screening for permanent positions. Others rely more extensively on temporary agencies for placing their clientele, especially those with weak skills and experience.

There is little disagreement among contractors about the benefits of using temporary agencies in temp-to-hire situations. However, when a company is screening for permanent employees through an agency, it is usually looking for workers whose skill levels would be at the

\footnotetext{
${ }^{8}$ A couple of contractors noted that it is more difficult to monitor employment status in temporary agencies and that some, who do not want permanent employment, use these jobs to give the appearance of complying with work requirements and hence game the system.
} 
high end of the skill distribution of Work First participants. Contractors noted that workers with some marketable skill are relatively easy to place in either direct-hire or temporary agency positions.

The real conundrum facing Work First providers concerns developing strategies for placing participants with very low skills, little or no work experience, or poor work ethics. Contractors are under considerable pressure to increase their job placement rates; typically, 40 to 50 percent of Work First participants leave the program without finding a job. As contractors readily pointed out, openings in direct-hire jobs for the least job-ready participants are often scant. A majority believed it is easier for these low-skilled workers to find jobs with temporary agencies.

Contractors sharply differed, however, in their views about whether those with weak skills and experience should be placed in agency jobs. On the one side, many believed that agency jobs can help these participants develop skills and a work ethic and that, for some participants, temporary employment is the only alternative to unemployment. On the other side, some contractors only endorsed an agency job when it is a temp-to-hire position. As expressed by one contractor, a temporary agency job "allows a person to stay compliant with Work First requirements, so they can't be terminated from the program. But, unless the job is temp-to-hire, they will end up back in the program. It could be in six months, it could be a year later, but they will end up back in the program, in the same place. They won't have made any advances.”

These divergent policies and practices are held by contractors who provide services to the same Work First population and operate in the same labor market. Coupled with random assignment of participants among contractors, these different practices, which result in different placement rates into temporary agency, direct-hire, or no job, enable us to identify the labor 
market effects of temporary agency placements. We turn now to a formal examination of these effects, with a particular focus on whether temporary agency jobs increase the probability that an individual will leave welfare and escape poverty.

\section{Do Temporary Help Agency Jobs Help Participants Escape Welfare and Poverty? Evidence from Administrative Data}

\section{Methodology for Identifying Effects of Temporary Agency Employment}

We apply the methodology we developed in Autor and Houseman (2005) to examine whether temporary agency jobs help participants achieve income levels sufficient to leave welfare and escape poverty. A key challenge for any empirical investigation of this sort is establishing causality. Simple comparisons of subsequent employment and earnings outcomes among those obtaining direct-hire jobs, temporary agency jobs, or no job while in the Work First program may be misleading because the average characteristics of individuals taking a directhire, a temporary agency, or no job differ. Whereas those placed into both temporary agency and direct-hire jobs earn substantially more over the subsequent two-year period than those not placed in any job, they also have significantly higher education levels and significantly higher

employment and earnings levels prior to Work First program entry (Autor and Houseman 2005). If there is significant selection on observable characteristics into job types (direct-hire, temp, or no job), it is likely that selection on unmeasured characteristics, such as motivation and employment barriers, is also important. These confounding factors make it difficult to disentangle the effects of type of job taken (temporary help, direct hire, no job) on subsequent labor market outcomes from the determinants of the jobs taken initially.

Several U.S. studies have endeavored to determine whether temporary agency jobs can facilitate the transition to employment among the low-skilled or low income unemployed and improve their longer-term employment and earnings outcomes (Andersson, Holzer, and Lane 
2005; Heinrich, Muser, and Troske 2005; Corcoran and Chen 2004; Lane et al. 2003; Ferber and Waldfogel 1998). These studies, all based on non-experimental data and methodologies, all find some evidence that temporary agency employment improves longer-term labor market outcomes. ${ }^{9}$

Our study is the first to use a quasi-experimental research design. As described above, in most geographic districts in our city, two or three contractors alternate in taking in new Work First participants. Contractors operating within the same district, in turn, may have different policies and contacts that influence the fraction placed in jobs and, among those, the fraction placed in direct-hire and temporary agency jobs. In Autor and Houseman (2005), we demonstrate that within nine geographic districts two critical assumptions that underlie our empirical strategy hold true. First, participants assigned to contractors operating within the same geographic district were insignificantly different across a broad set of demographic characteristics and in their prior employment and earnings history, and thus the assignment of participants to contractors was consistent with random assignment. Second, there were large, persistent, and significant differences in the fraction of participants placed in temp, direct-hire, or no job across contractors operating in the same district.

We exploit these cross-contractor differences in the probabilities of being placed in a direct-hire, temp, or no job among statistically identical populations living in the same neighborhood to identify the effects of a temporary agency placement, relative to a direct-hire or no job placement, on earnings outcomes over a two-year period following program entry. We directly address the policy question of interest: Is placing workers in temporary agency jobs a viable strategy for moving additional low-skilled workers out of poverty? It is critical to bear in

\footnotetext{
${ }^{9}$ A number of studies of the role of temporary employment (temporary agency and fixed-term contract employment) in labor market transitions in Europe have been conducted. For a description and critique of methods used in these U.S. and European studies, see Autor and Houseman (2005).
} 
mind that the effect of a temporary agency job may not be the same for all individuals. Indeed, our survey showed that contractors often distinguish between types of workers when assessing whether agency placements are beneficial. Even if, on average, those who take an agency job derive long-term labor market benefits, it does not mean that a policy to increase placements with temporary help agencies will benefit the individuals impacted by the policy change, because the effects of temporary agency placements for the average temporary help worker may differ from the effects for the marginal temporary help worker. ${ }^{10}$

Our quasi-experimental research design allows us to measure the effects of marginal temporary agency placements. That is, we identify whether a temporary agency placement, relative to no job placement or a direct-hire job placement, improves or harms labor market outcomes for those whose job placement status is impacted by contractor assignment. Descriptive Statistics on the Characteristics of Temporary Help Agency and Direct-Hire Jobs

In our sample of Work First spells, 47 percent resulted in some job placement. Among spells resulting in jobs, 21 percent were with temporary help agencies. Figure 1 compares the occupational distribution of temporary agency and direct-hire jobs. Temporary agency jobs were heavily concentrated in a subset of occupations. Almost one-third of the agency jobs were in production occupations and 23 percent were in manual, general laborer positions. Health care and clerical occupations each accounted for about 14 percent of agency jobs. Direct-hire jobs were more dispersed across occupational categories. The large differential between the fraction of temporary agency and direct-hire jobs in production occupations reflects the extensive use of temporary help agencies by manufacturers to staff low-skilled positions. ${ }^{11}$

\footnotetext{
${ }^{10}$ There is a large and growing literature on the heterogeneity of treatment effects. See for example Angrist (2004) and Heckman and Vytlacil (2005).

${ }^{11}$ The occupational distribution of temporary agency jobs in our sample is broadly consistent with available national data from the Occupational Employment Survey. According to the OES, production and clerical
} 
Many contractors ranked temporary agency jobs less favorably than direct-hire jobs in terms of their wage levels and weekly hours. Our administrative data, however, show that the mean hourly wage (\$7.69 vs. \$7.23) and weekly hours (37 vs. 34) - and in fact the entire distribution of wages and hours - are uniformly higher for temporary agency than for direct-hire jobs (Table 4). This fact reflects, in part, the different occupational distribution of temporary agency and direct-hire jobs displayed in Figure 1.

Econometric Evidence on the Effects of Temporary Agency Employment on Welfare Dependency and Poverty

Descriptive evidence on the wages and hours of temporary agency jobs compared to direct-hire jobs suggests that the former are no worse—and possibly better-than the direct-hire jobs participants obtain. Though we caution that these simple comparisons should not be taken as causal, the evidence in Table 4 underscores that temporary agency positions may confer benefits, at least in the short run. Whether over the longer term temporary agency jobs help the lowskilled end welfare dependence and escape poverty depends on whether they help workers transition to stable employment.

To formally examine this issue, we estimate the following econometric model:

$$
y_{\text {icdt }}=\alpha+\beta_{1} T_{i}+\beta_{2} D_{i}+X_{i}^{\prime} \lambda+\gamma_{d}+\theta_{t}+\left(\gamma_{d} \times \theta_{t}\right)+\varepsilon_{\text {idtc }},
$$

where $y_{\text {icdt }}$ is the outcome of interest for a participant in Work First spell $i$, with contractor $c$, in district $d$, and in program year $t ; D_{i}$ and $T_{i}$ are dummy variables indicating the participant was placed in a direct-hire or temporary agency job, respectively; $X_{i}$ is a vector of characteristics including gender, race, age and age-squared, highest level of education achieved, and earnings in

occupations accounted for the greatest concentration of temporary agency jobs, each accounting for about a third of employment in 2000. The relatively low concentration of clerical occupations in our sample no doubt reflects the low skills level of our population. According to contractors surveyed, temporary clerical positions tend to require higher skill levels than most of their clientele have. 
the four quarters prior to the quarter of Work First entry; $\gamma$ is a vector of district dummy

variables, and $\theta$ is a vector of quarter-year dummy variables.

We first estimate this model using ordinary least squares and then follow with two-stage least squares estimates. In the two-stage least squares model, we instrument for the indicator variables $D_{i}$ and $T_{i}$ — that is, whether the participant obtained a direct-hire or temporary agency job-using contractor and contractor-program year dummy variables. We report robust standard errors, allowing for clustering of the error term on contractor assignment by program year. ${ }^{12}$

As noted above, the effects of temporary agency or direct-hire jobs on the outcome of interest are estimated for individuals whose job placement type is changed by contractor assignment. In Autor and Houseman (2005) we show that, on the margin, those placed into temporary agency and direct-hire jobs have significantly weaker prior work histories than does the average worker placed into temporary agency and direct-hire positions. This finding makes sense; when contractors increase job placements, whether it be with direct-hire or temporary agency employers, they place participants who, on average, have weaker skills and experience than those initially placed. ${ }^{13}$ Conceptually, then, our 2SLS estimates of $\beta_{1}$ and $\beta_{2}$ in Equation (1) indicate how a "marginal” worker among the Work First population-that is, an individual with relatively weak skills and experience-would fare over time if she were placed in a direct-hire job or a temporary agency job relative to no job at all.

\footnotetext{
${ }^{12}$ The unit of observation is the Work First spell. We do not correct for potential clustering of the error term for individuals with multiple spells in our data. However, limiting the sample to the first spell yields virtually identical results to those reported here.

13 This finding is also consistent with our survey results, which show that the debate among contractors over temporary help agencies pertains primarily to whether or not agency placements benefit or harm those with weaker skills and experience. Thus, we would expect that the contractors with relatively high temporary agency placement rates would be placing relatively more participants with weak skills and experience into those agency jobs. In turn, for the whole sample, we would expect marginal temporary agency workers to have, on average, weaker skills and experience.
} 
Estimating equation (1), we show in earlier work that both direct-hire and temporary agency placements significantly increase participants' employment and earnings relative to no job placement over the short-term—one quarter following the quarter of program entry. However, whereas direct-hire placements significantly increase participants' employment and earnings for up to two years following program entry relative to no job placement, the positive labor market effects of temporary agency job placements are short-lived. Two to eight quarters following program entry, temporary agency placements result in no increase in employment and earnings relative to no job placement; they also result in significantly lower employment rates and labor earnings relative to direct-hire job placements.

We extend the analysis here to consider whether temporary agency placements help participants leave welfare and escape poverty - which is the ultimate goal of welfare policy and the Work First program in particular. We use several measures of welfare dependency and poverty to study this issue. The first comes from the Work First administrative data. When individuals leave the Work First program, the reason for program termination is coded. One code indicates that the participant has obtained a job providing a stream of income sufficient to close her TANF case ("terminated because of earnings"). This is the immediate and explicit goal of the program, so a case closed because of earnings is an indicator of program success. About 18 percent of Work First spells in our sample are terminated because of earnings. Those who fail to find a job while in the program are terminated for other reasons, mostly because they fail to comply with program rules or refuse to continue. Among those finding a job in the Work First program, about 38 percent with a direct-hire job and 33 percent with a temporary agency job achieve earnings levels sufficient to close their TANF case during their Work First spell. 
We estimate Equation (1) with a dummy dependent variable indicating whether or not the participant achieved sufficient earnings during the spell to close her welfare case. ${ }^{14}$ Selected coefficients from the OLS and Instrumental Variables (IV) models are reported in Table 5. In the OLS models, the coefficients on the variables indicating the participant held a temporary agency (33.0) or direct-hire job (37.6) while in Work First reflect the percent in each category whose case was closed because of earnings. We stress that although these OLS models include controls for demographic characteristics and prior earnings, the results are purely descriptive.

By contrast, the two-stage least squares models have a causal interpretation. Notably, the coefficient estimates in column 2 of Table 5 are both smaller than the OLS coefficients in column 1. The coefficient on the direct-hire variable remains highly significant, however, and indicates that direct-hire placements increase the probability of successful program termination by 24.6 percentage points. The coefficient estimate on the temporary agency variable (11.5), while still positive, is insignificantly different from zero. The 2SLS models do not support the inference that temporary agency jobs significantly increase the probability of successful earnings-based case closure, though they do demonstrate that direct-hire job placements substantially increase this probability.

Termination of TANF benefits as a result of a job obtained in the Work First program is highly relevant to contractors because they are evaluated on this measure. From a broader policy perspective, however, this measure has potential flaws. First, those who do not find a job while in the Work First program may find employment on their own and leave welfare, yet they are not counted as “successes” by this measure. Second, individuals who are terminated because of

\footnotetext{
${ }^{14}$ Information on the reason for case closure was missing for 1,595 spells, and these observations were dropped from the sample.
} 
earnings may lose their job and end up back on welfare benefits and in Work First in a relatively short period of time.

To surmount these limitations, we examine measures that indicate whether, over longer time horizons, participants achieved earnings sufficient to end welfare dependency and escape poverty. Because we cannot compute individual-level welfare and poverty thresholds with our data (since they do not include information on family composition), we select a variety of welfare and poverty thresholds as outcome measures: earnings needed to terminate welfare benefits for a family of three and for a family of four (typically a mother with two or three dependent children) and earnings exceeding the poverty level for a family of three with two dependent children or a family of four with three dependent children. ${ }^{15}$

Table 6 reports descriptive statistics for the percent of Work First participants with earnings above these thresholds over various time horizons for those obtaining a direct-hire, temporary agency, or no job while in the program. The income threshold for welfare benefits is considerably below the poverty level for any given family size. The income level above which a family's welfare benefits would be cut was 64 percent of the poverty level for a family of three with two dependent children and 59 percent for a family of four with three dependent children in 2003. $^{16}$

Relatively few participants attain earnings even above the lowest threshold. For instance, in the first four quarters following program entry, the percent with earnings exceeding the welfare threshold level for a family of three, $\$ 9,504$ in annual earnings, was 9.1 percent for those

\footnotetext{
${ }^{15}$ Welfare thresholds change infrequently. Therefore, to assess whether a participant's earnings exceeded a threshold, we compared unadjusted earnings to the welfare threshold applying during the time period. For poverty thresholds, we used 2003 Census Bureau definitions, which are defined only at the national level, and adjusted both earnings and poverty thresholds for inflation to 2003 levels using the Consumer Price Index.

${ }^{16}$ Those not eligible for TANF may still be eligible for Food Stamps, other assistance, and the Earned Income Tax Credit, and thus the discrepancy between welfare and poverty thresholds may be smaller once these benefits are taken into account.
} 
with no job in Work First, 22.1 percent for those with a direct-hire job, and 21.3 percent for those with a temporary agency job. The fraction earning above the poverty threshold for a family of four with three dependent children in the first year following the quarter of program entry is 5 percent or less for all groups.

Paralleling the analysis reported in Table 5, we use Equation (1) to estimate a series of models with dummy-dependent variables indicating earnings above each of the four thresholds over the various time horizons. The first panel of Table 7 reports coefficient estimates pertaining to the welfare and poverty thresholds for the first quarter following program entry; the second panel for the second through fourth quarters following program entry; the third panel for the combined first through fourth quarters; and the last panel for the fifth through eighth quarters following the quarter of program entry.

Our 2SLS estimates of the effects of job placement on short-term earnings are generally similar to the OLS estimates. The 2SLS models indicate that for three out of the four thresholds, temporary agency placements significantly raise the probability (relative to no job placement) that participants' earnings will exceed the welfare or poverty threshold in the near term - that is, the first quarter following program entry.

The IV models also indicate that, relative to no job placement, direct-hire placements significantly increase the probability that participants' earnings in the first quarter exceed the two welfare thresholds. From Table 7, column 4, for instance, we estimate that a temporary agency placement increases by 14.8 percentage points the probability that a participant's earnings in the first quarter following the quarter of entry will exceed the welfare threshold for a family of four, whereas a direct-hire placement increases that probability by 9.6 percentage points. 
Results from our IV models portray a distinctly different picture when we evaluate the effects of job placements on earnings over a longer time horizon. Direct-hire placements significantly raise the probability that participant earnings will exceed the income level necessary for a family of three or four to remain off of welfare for up to two years following the quarter of program entry. Relative to no job placement, placing an individual in a direct-hire job increases the likelihood that her earnings will exceed the welfare threshold for a family of four by 5.9 percentage points over the first year following the quarter of program entry and by 10.8 percentage points for the second year following the quarter of program entry.

In contrast, the initial positive effects of temporary agency placements disappear over longer time horizons. Over the first and the second year following program entry, the IV estimates of the effects of temporary agency placements on the probability of earning above welfare thresholds are negative, though small and insignificantly different from zero. Thus, marginal temporary agency placements do not appear to help participants stay off of welfare.

For higher thresholds, as represented by the poverty threshold for a family of three and for a family of four, we find that neither temporary agency nor direct-hire placements help participants escape poverty over a one-to-two-year period following program entry. In fact, relative to no job and to a direct-hire job placement, placements into temporary agency jobs actually have modest but significant negative effects on the probability that participants earn above the poverty threshold for a family of four over the four quarters following program entry.

In summary, we find that placements in temporary agency jobs help participants escape welfare and poverty only in the short term. Over longer horizons, these placements do not increase, and may even reduce, participants' chances of attaining earnings levels sufficient to leave welfare and escape poverty. In contrast, placements in direct-hire jobs modestly increase 
the chances that participants will earn enough to leave welfare, though we find no significant effects of marginal direct-hire jobs on the probability of exceeding poverty thresholds.

\section{Conclusions}

In contrast to previous studies, we find no evidence that would support a policy recommendation that employment programs should increase the use of temporary agencies as labor market intermediaries for low-skilled workers. Although temporary agency job placements do raise the probability that Work First participants will earn above welfare and poverty thresholds over very short time horizons, these positive effects quickly dissipate. Over horizons of one to two years, placements in temporary agency jobs (relative to no job placement) do not increase the chances that participants will earn enough to leave welfare and escape poverty. Moreover, by some measures, these placements reduce the chances that earnings will exceed poverty thresholds. Our results suggest raising direct-hire placements are likely to be a much more effective means for job assistance programs to reduce welfare dependency over both the short and long term. Even marginal direct-hire placements, however, do not appear to improve participants' chances of escaping poverty over longer time horizons.

It must be emphasized that our results do not imply that temporary agency jobs never improve long-term participant outcomes. Our estimates pertain only to "marginal” workers— that is, to participants whose job placement is affected by random assignment among contractors. As we show in Autor and Houseman (2005), these marginal temporary help agency and directhire workers have weaker skills and experience than the average participant placed into a job. To the degree that there is heterogeneity among temporary agency jobs or workers, the effects of 
temporary agency placements may differ between the marginal and infra-marginal placement. ${ }^{17}$ Our survey evidence, for instance, revealed some consensus among contractors that temp-toperm jobs, which tend to be taken by relatively high-skilled participants, are often beneficial but we cannot formally test this proposition with our data. Nevertheless, our findings are particularly germane to the design of welfare programs. The operative question for program design is whether job programs assisting welfare and other low-wage workers can improve participants’ labor market outcomes by placing more clients with temporary agency positions. Our analysis suggests not.

Among marginal temporary help workers (i.e., those with relatively weak skills and experience), why do agency jobs fail to provide lasting benefits and potentially even harm participants’ long-term labor market outcomes? Although we cannot provide definitive answers to this critical question, our survey evidence and statistical analysis suggest some plausible explanations. Work First contractors reported that temporary agency jobs were relatively more plentiful than direct-hire jobs for those with weak skills and experience, but that these agency jobs generally did not lead to permanent positions. Reinforcing these perceptions, Autor and Houseman (2005) estimate that temporary agency placements subsequently result in increased earnings in the temporary help sector but in reduced earnings in direct-hire jobs. Thus, those placed in temporary agency jobs are more likely than average participants to continue to work in the temporary help sector. To the extent that these temporary jobs lead to shorter job durations and more frequent unemployment spells, they may generate lower earnings and lesser employment stability over the long term than direct-hire jobs. Lending some weight to this concern, two-stage least squares estimates in Autor and Houseman (2005) indicate that

\footnotetext{
${ }^{17}$ Heterogeneity of effects between marginal and infra-marginal workers may partly explain the differences of our results from those of previous studies. For an extensive discussion of this issue, see Autor and Houseman (2005).
} 
participants placed in temporary help jobs during their Work First spell are significantly more likely to experience another spell of welfare receipt within two years than are participants placed in direct-hire jobs.

One perspective expressed in our contractor survey was that a certain segment of the temporary agency market accommodated individuals with very weak skills, experience, and work ethic by providing them with jobs that require few skills and no long-term commitment. Yet it is the lack of skills, experience, and work ethic that keeps these individuals in poverty. While temporary agency positions may help these individuals to fulfill program work requirements in the short term, these appear ineffective at reducing their dependency on welfare. Job placements that might help participants to overcome, rather than accommodate, their employment barriers may be more beneficial.

We conclude that in some circumstances it would be better for individuals to pass up an opportunity to work for a temporary agency and to continue to search for direct-hire employment. Yet, the incentives built into the Work First program for both participants and contractors may not support such a decision. Participants are encouraged to obtain work quickly and officially are required to accept any employment offering the minimum wage and sufficient hours. Contractors are primarily evaluated on job placement rates and 90-day retention rates, and over such short time horizons temporary agency placements do yield benefits. Moving to an incentive structure that places greater weight on longer-term outcomes may reduce welfare dependence and poverty levels by mitigating short-term pressures on program providers to place participants into any job available, including potentially counter-productive ones. 


\section{References}

Abraham, Katharine G. 1988. "Flexible Staffing Arrangements and Employers' Short-Term Adjustment Strategies.” In Robert A. Hart, ed. Employment, Unemployment, and Labor Utilization. Boston: Unwin Hyman.

Andersson, Frederik, Harry J. Holzer, and Julia I. Lane. 2005. Moving Up or Moving On: Who Advances in the Labor Market? New York: Russell Sage Foundation.

Angrist, Joshua D. 2004. "Treatment Effect Heterogeneity in Theory and Practice.” Economic Journal 114(494): March, C52-83.

Autor, David H. 2001. "Why Do Temporary Help Firms Provide Free General Skills Training?” Quarterly Journal of Economics 116(4): 1409-1448.

Autor, David H. 2003. "Outsourcing at Will: The Contribution of Unjust Dismissal Doctrine to the Growth of Employment Outsourcing.” Journal of Labor Economics 21(1): 1-42.

Autor, David H., and Susan N. Houseman. 2002. “The Role of Temporary Employment Agencies in Welfare to Work: Part of the Problem or Part of the Solution?” Focus 22(1): 63-70.

Autor, David H., and Susan N. Houseman. 2005. "Do Temporary Help Jobs Improve Labor Market Outcomes for Low-Skilled Workers? Evidence from Random Assignments.” Unpublished manuscript.

Corcoran, Mary, and Juan Chen. 2004. “Temporary Employment and Welfare-to-Work.” Unpublished paper. University of Michigan, Ann Arbor, MI.

Ferber, Marianne A., and Jane Waldfogel. 1998. “The Long-Term Consequences of Nontraditional Employment.” Monthly Labor Review 121(5): 3-12.

Heckman, James J., and Edward Vytlacil. 2005.“Structural Equations, Treatment Effects and Econometric Policy Evaluation.” NBER Working Paper No. 11,259. Cambridge, MA: National Bureau of Economic Research.

Heinrich, Carolyn J., Peter R. Mueser, and Kenneth R. Troske. 2005. "Welfare to Temporary Work: Implications for Labor Market Outcomes.” Review of Economics and Statistics 87(1): 154-173.

Holzer, Harry J. 2004. "Encouraging Job Advancement among Low-Wage Workers: A New Approach.” Brookings Institution Policy Brief: Welfare Reform and Beyond \#30. 2004 (May): 1-8.

Houseman, Susan N. 2001. "Why Employers Use Flexible Staffing Arrangements: Evidence from an Establishment Survey.” Industrial and Labor Relations Review 55(1): 149-170. 
Kalleberg, Arne L., Jeremy Reynolds, and Peter V. Marsden. 2003. "Externalizing Employment: Flexible Staffing Arrangements in U.S. Organizations.” Social Science Research 32(December): 525-552.

Lane, Julia, Kelly S. Mikelson, Pat Sharkey and Doug Wissoker. 2003. "Pathways to Work for Low-Income Workers: The Effect of Work in the Temporary Help Industry.” Journal of Policy Analysis and Management 22(4): 581-598. 
Table 1. Frequency of Temp Agency Visits and Referrals to Agencies (percent of contractors reporting frequency)

\begin{tabular}{lccccc}
\hline & Weekly & Monthly & $\begin{array}{c}\text { Every few } \\
\text { months }\end{array}$ & Sporadically & Never \\
\hline Invite temp agencies on-site & 4.8 & 9.5 & 19.1 & 38.1 & 28.6 \\
Refer participants to jobs at temp agencies & 23.8 & 33.3 & 4.8 & 28.6 & 9.5 \\
\hline
\end{tabular}

Tabulations based on survey responses from 21 Work First contractors. 
Table 2. Comparison of the Characteristics of Temp Agency and Direct-Hire Jobs: Contractors' Views (percent reporting)

\begin{tabular}{|c|c|c|c|c|}
\hline & Direct-hire better & Temp better & Same & Don’t know \\
\hline Hours per week & 57.1 & 0.0 & 23.8 & 19.1 \\
\hline Hourly pay & 57.1 & 9.5 & 19.1 & 14.3 \\
\hline Job stability/duration & 76.2 & 4.8 & 9.5 & 9.5 \\
\hline Transportation issues ${ }^{\mathrm{a}}$ & 20.0 & 15.0 & 45.0 & 20.0 \\
\hline $\begin{array}{l}\text { Accommodate clients' needs for } \\
\text { flexibility or scheduling work } \\
\text { hours }\end{array}$ & 19.1 & 61.9 & 14.3 & 4.8 \\
\hline $\begin{array}{l}\text { Willingness to accommodate } \\
\text { participants' special issues }\end{array}$ & 19.1 & 23.8 & 42.9 & 14.3 \\
\hline Treat participants well & 23.8 & 14.3 & 47.6 & 14.3 \\
\hline
\end{tabular}

Tabulations based on survey responses from 21 Work First contractors.

${ }^{\mathrm{a}}$ Tabulations based on 20 responses. 
Table 3. Longer-Term Consequences of Temp Help Jobs (percent responding)

\begin{tabular}{|c|c|c|c|c|}
\hline & Rarely & Occasionally & Frequently & $\begin{array}{l}\text { Most of the } \\
\text { time }\end{array}$ \\
\hline Help participants build skills & 23.8 & 28.6 & 38.1 & 9.5 \\
\hline Help participants improve work habits & 33.3 & 23.8 & 33.3 & 9.5 \\
\hline Help participants develop confidence & 19.1 & 23.8 & 42.9 & 14.3 \\
\hline Generate contacts that may lead to other jobs & 19.1 & 33.3 & 28.6 & 19.1 \\
\hline Result in temp-to-hire positions & 33.3 & 42.9 & 19.1 & 4.8 \\
\hline $\begin{array}{l}\text { Prevent participants from searching for better, possibly } \\
\text { direct-hire, jobs }\end{array}$ & 47.6 & 9.5 & 33.3 & 9.5 \\
\hline $\begin{array}{l}\text { Allow participants to avoid making a serious } \\
\text { employment commitment }\end{array}$ & 38.1 & 19.1 & 23.8 & 19.1 \\
\hline
\end{tabular}

Tabulations based on survey responses from 21 Work First contractors. 
Table 4. Comparison between Temp and Direct-Hire Jobs of the Distribution of Hourly Wages, Weekly Hours, and Weekly Earnings

\begin{tabular}{|c|c|c|c|c|c|}
\hline & Mean & & ercentile & & \\
\hline & (std. error) & 10th & 50th & 90th & $\mathrm{N}$ \\
\hline \multicolumn{6}{|c|}{ Hourly wages (\$) } \\
\hline Temp & $\begin{array}{c}7.69 \\
(0.03)\end{array}$ & 5.75 & 7.00 & 10.00 & 3,286 \\
\hline Direct-hire & $\begin{array}{c}7.23 \\
(0.02)\end{array}$ & 5.15 & 7.00 & 9.50 & 13,709 \\
\hline \multicolumn{6}{|c|}{$\underline{\text { Weekly hours }}$} \\
\hline Temp & $\begin{array}{c}37.01 \\
(0.10)\end{array}$ & 30 & 40 & 40 & 3,286 \\
\hline Direct-hire & $\begin{array}{c}33.54 \\
(0.06)\end{array}$ & 20 & 35 & 40 & 13,709 \\
\hline \multicolumn{6}{|c|}{ Weekly earnings (\$) } \\
\hline Temp & $\begin{array}{r}284.38 \\
(1.43)\end{array}$ & 200 & 280 & 400 & 3,286 \\
\hline Direct-hire & $\begin{array}{r}245.78 \\
(0.80)\end{array}$ & 140 & 240 & 360 & 13,709 \\
\hline
\end{tabular}

Wages and earnings data were inflated to 2003 dollars using the Consumer Price Index (CPI). 
Table 5. The Effect of Work First Job Placements on the Probability of Having Welfare Case Closed due to Earnings

\begin{tabular}{lccc}
\hline & $\begin{array}{c}\text { Percent of cases closed } \\
\text { because of earnings }\end{array}$ & OLS & 2SLS \\
\hline Temp agency job & 32.9 & $33.0^{* *}$ & 11.5 \\
& & $(1.8)$ & $(11.1)$ \\
Direct-hire job & 37.6 & $37.6^{* *}$ & $24.6^{* *}$ \\
& & $(1.4)$ & $(7.1)$ \\
$\mathrm{R}^{2}$ & 0.24 & 0.20 \\
$\mathrm{H}_{0}:$ Temp = Direct & & 0.00 & 0.41 \\
\hline
\end{tabular}

** indicates significance at the 0.05 level; $*$ indicates significance at the 0.10 level. Number of observations $=$ 34,510. Robust standard errors in parentheses are clustered on Work First contractor assignment $\times$ year. All models include year $\times$ quarter of assignment and randomization-district $\times$ year of assignment dummy variables, and controls for age and its square, race, sum of UI earnings in four quarters prior to Work First assignment, and four education dummies (elementary education, less than high school, greater than high school, and education unknown). Coefficient estimates and standard errors are multiplied by 100 . 
Table 6. Percent with Earnings Sufficient to Escape Welfare or Poverty, by Time from Work First Orientation and by Job Type, Various Thresholds

\begin{tabular}{|c|c|c|c|c|}
\hline & $\begin{array}{l}\text { Welfare threshold, } \\
\text { family of } 3\end{array}$ & $\begin{array}{l}\text { Welfare threshold, } \\
\text { family of } 4\end{array}$ & $\begin{array}{l}\text { Poverty threshold, } \\
\text { family of } 3\end{array}$ & $\begin{array}{l}\text { Poverty threshold, } \\
\text { family of } 4\end{array}$ \\
\hline & \multicolumn{4}{|c|}{ Quarter 1} \\
\hline No job & 6.7 & 5.4 & 3.4 & 2.1 \\
\hline Direct-hire job & 21.3 & 17.0 & 9.9 & 5.2 \\
\hline \multirow[t]{2}{*}{ Temp job } & 21.1 & 16.4 & 9.7 & 5.2 \\
\hline & \multicolumn{4}{|c|}{ Quarters 1-4 } \\
\hline No job & 9.1 & 7.1 & 4.2 & 2.2 \\
\hline Direct-hire job & 22.1 & 17.5 & 10.0 & 5.3 \\
\hline \multirow[t]{2}{*}{ Temp job } & 21.3 & 17.1 & 9.5 & 5.4 \\
\hline & \multicolumn{4}{|c|}{ Quarters 5-8 } \\
\hline No job & 12.2 & 10.1 & 8.8 & 5.1 \\
\hline Direct-hire job & 19.8 & 16.5 & 15.0 & 8.5 \\
\hline Temp job & 19.3 & 16.0 & 14.5 & 8.9 \\
\hline
\end{tabular}


Table 7. The Effect of Work First Job Placements on the Probability of Escaping Poverty One to Eight Quarters Following Work First Assignment

\begin{tabular}{|c|c|c|c|c|c|c|c|c|}
\hline & \multicolumn{2}{|c|}{$\begin{array}{c}\text { Welfare threshold, } \\
\text { family of } 3\end{array}$} & \multicolumn{2}{|c|}{$\begin{array}{c}\text { Welfare threshold, } \\
\text { family of } 4\end{array}$} & \multicolumn{2}{|c|}{$\begin{array}{l}\text { Poverty threshold, } \\
\text { family of } 3\end{array}$} & \multicolumn{2}{|c|}{$\begin{array}{l}\text { Poverty threshold, } \\
\text { family of } 4\end{array}$} \\
\hline & OLS & 2SLS & OLS & 2SLS & OLS & $2 S L S$ & OLS & 2SLS \\
\hline & $(1)$ & $(2)$ & (3) & $(4)$ & $(5)$ & $(6)$ & $(7)$ & $(8)$ \\
\hline & \multicolumn{8}{|c|}{ First Quarter } \\
\hline Temp agency job & $\begin{array}{r}12.4^{* *} \\
(0.9)\end{array}$ & $\begin{array}{c}17.6^{* *} \\
(4.3)\end{array}$ & $\begin{array}{l}9.2^{* *} \\
(0.8)\end{array}$ & $\begin{array}{c}14.8^{* *} \\
(3.6)\end{array}$ & $\begin{array}{c}5.0^{* *} \\
(0.6)\end{array}$ & $\begin{array}{l}8.8^{* *} \\
(2.2)\end{array}$ & $\begin{array}{l}2.2^{* *} \\
(0.4)\end{array}$ & $\begin{array}{c}2.9 \\
(1.9)\end{array}$ \\
\hline Direct-hire job & $\begin{array}{r}13.3^{* *} \\
(0.5)\end{array}$ & $\begin{array}{c}12.2 * * \\
(2.1)\end{array}$ & $\begin{array}{c}10.3^{* *} \\
(0.4)\end{array}$ & $\begin{array}{l}9.6^{* *} \\
(2.1)\end{array}$ & $\begin{array}{l}5.5^{* *} \\
(0.3)\end{array}$ & $\begin{array}{c}0.7 \\
(1.4)\end{array}$ & $\begin{array}{l}2.4^{* *} \\
(0.2)\end{array}$ & $\begin{array}{l}-0.6 \\
(1.1)\end{array}$ \\
\hline $\mathrm{R}^{2}$ & 0.11 & & 0.11 & & 0.09 & & 0.07 & \\
\hline $\mathrm{H}_{0}:$ Temp $=$ Direct & 0.41 & 0.26 & 0.22 & 0.26 & 0.42 & 0.01 & 0.67 & 0.17 \\
\hline & \multicolumn{8}{|c|}{ Quarters 1 - 4} \\
\hline Temp agency job & $\begin{array}{r}9.8^{* *} \\
(0.9)\end{array}$ & $\begin{array}{l}-0.3 \\
(5.8)\end{array}$ & $\begin{array}{l}7.8^{* *} \\
(0.8)\end{array}$ & $\begin{array}{l}-0.9 \\
(4.4)\end{array}$ & $\begin{array}{c}3.7^{* *} \\
(0.5)\end{array}$ & $\begin{array}{l}-1.0 \\
(3.0)\end{array}$ & $\begin{array}{l}2.3^{* *} \\
(0.4)\end{array}$ & $\begin{array}{l}-4.1^{*} \\
(2.1)\end{array}$ \\
\hline Direct-hire job & $\begin{array}{r}11.1^{* *} \\
(0.4)\end{array}$ & $\begin{array}{l}6.7^{* *} \\
(3.2)\end{array}$ & $\begin{array}{l}8.7^{* *} \\
(0.4)\end{array}$ & $\begin{array}{l}5.9 * * \\
(2.6)\end{array}$ & $\begin{array}{l}4.6^{* *} \\
(0.3)\end{array}$ & $\begin{array}{c}0.7 \\
(1.3)\end{array}$ & $\begin{array}{l}2.3^{* *} \\
(0.2)\end{array}$ & $\begin{array}{l}2.5^{*} \\
(1.3)\end{array}$ \\
\hline $\mathrm{R}^{2}$ & 0.14 & & 0.13 & & 0.10 & & 0.08 & \\
\hline $\mathrm{H}_{0}:$ Temp $=$ Direct & 0.16 & 0.35 & 0.30 & 0.24 & 0.16 & 0.61 & 0.88 & 0.01 \\
\hline & \multicolumn{8}{|c|}{ Quarters 5 - 8} \\
\hline Temp agency job & $\begin{array}{r}6.8^{* *} \\
(1.0)\end{array}$ & $\begin{array}{l}-4.5 \\
(6.7)\end{array}$ & $\begin{array}{l}5.6^{* *} \\
(0.9)\end{array}$ & $\begin{array}{l}-2.77 \\
(6.7)\end{array}$ & $\begin{array}{c}3.7^{* *} \\
(0.7)\end{array}$ & $\begin{array}{l}-5.8 \\
(5.5)\end{array}$ & $\begin{array}{l}2.2^{* *} \\
(0.5)\end{array}$ & $\begin{array}{l}-3.5 \\
(4.5)\end{array}$ \\
\hline Direct-hire job & $\begin{array}{r}8.3^{* *} \\
(0.6)\end{array}$ & $\begin{array}{c}15.1^{* *} \\
(4.9)\end{array}$ & $\begin{array}{l}7.0^{* *} \\
(0.5)\end{array}$ & $\begin{array}{c}10.8^{* *} \\
(4.8)\end{array}$ & $\begin{array}{l}4.5^{* *} \\
(0.4)\end{array}$ & $\begin{array}{c}6.3 \\
(4.4)\end{array}$ & $\begin{array}{l}2.2^{* *} \\
(0.3)\end{array}$ & $\begin{array}{c}3.4 \\
(3.2)\end{array}$ \\
\hline $\mathrm{R}^{2}$ & 0.12 & & 0.12 & & 0.11 & & 0.09 & \\
\hline $\mathrm{H}_{0}$ : Temp = Direct & 0.20 & 0.05 & 0.17 & 0.17 & 0.36 & 0.11 & 0.92 & 0.25 \\
\hline
\end{tabular}

** indicates significance at the 0.05 level; * indicates significance at the 0.10 level. Number of observations $=$ 36,105 in panels labeled Quarter 1 and Quarters 1-4 and represent Work First participants entering from third quarter 1999 through second quarter 2003. The last panel labeled Quarters 5-8 is based on participants entering from the third quarter 1999 through the second quarter of 2002 and has 25,118 observations. Robust standard errors in parentheses are clustered on Work First contractor assignment $\times$ year. All models include year $\times$ quarter of assignment and randomization district $\times$ year of assignment dummy variables, and controls for age and its square, race, sum of UI earnings in four quarters prior to Work First assignment, and four education dummies (elementary education, less than high school, greater than high school, and education unknown). Coefficient estimates and standard errors are multiplied by 100 . 
Figure 1: Occupational Distribution of Temporary Help Agency and Direct-Hire Jobs

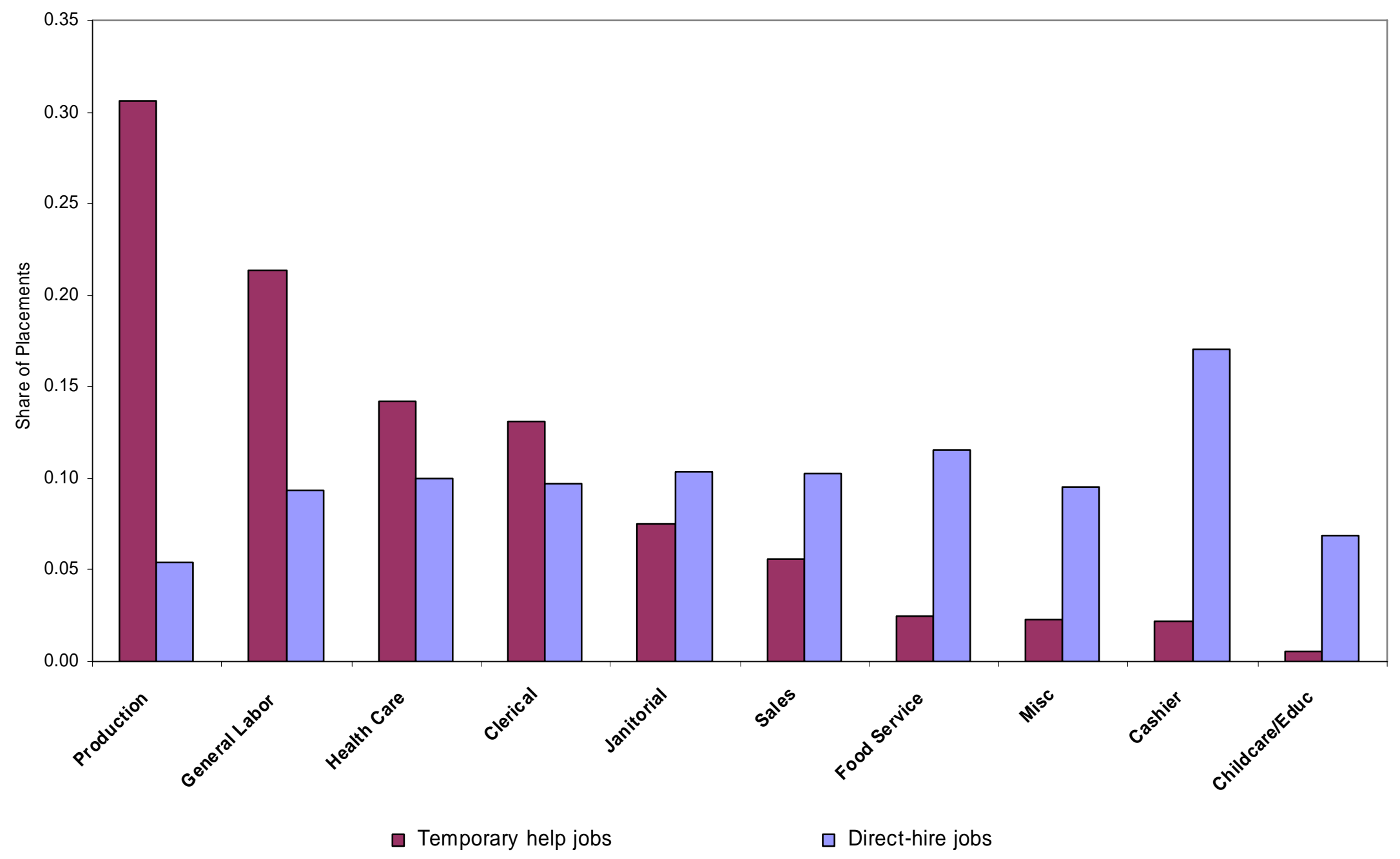

